\title{
O recurso do método de pareamento por escore de propensão em ensaios clínicos
}

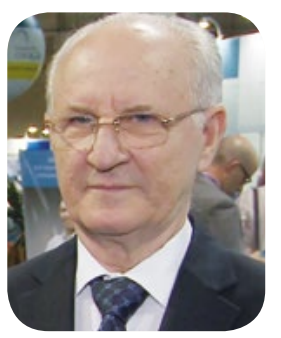

Ao se tentar estabelecer o valor de uma intervenção terapêutica tem-se como o melhor modelo de investigação compará-la a um grupo-controle, utilizando-se para isso um grupo de indivíduos afetados pelo processo mórbido a ser tratado, aleatoriamente destinados a se submeter à intervenção em questão ou à intervenção-controle - placebo ou tratamento já comprovado.

Dessa maneira, a diferença porventura constatada nos desfechos observados poderá ser atribuída à propriedade da intervenção realizada, já que, de saída, as distintas variáveis que poderiam influenciar na verificação do desfecho tiveram, na randomização, principalmente quando o número de casos incluídos for adequado, iguais chances de se verem representadas nos dois grupos tratados.

Ocorre que nem sempre é possível a realização de estudos randomizados.

Em estudos não-randomizados, observacionais, onde se pretende comparar o efeito de duas estratégias de tratamento, quando do início da instituição dos tratamentos, fica impossibilitada a equalização de chances de que os dois grupos tivessem características semelhantes.

Dada a desigualdade de variáveis no início do tratamento, e podendo algumas delas influenciar decisivamente no determinismo do desfecho a se verificar, ficará, ao final da comparação, a dúvida se as diferenças constatadas são atributos do tratamento oferecido ou estão sendo vistas por conta da influência destas variáveis, chamadas de confundimento.

A tentativa de corrigir este problema tem sido feita com análise de regressão uni e multivariável, a partir dos desfechos observados.

A partir de 1983, uma outra forma proposta para esta tentativa de correção é a de pareamento por es-

\author{
Gilson Soares Feitosa ${ }^{1}$
}

core de propensão de pertencer a um dos grupos, de acordo com as características basais observadas, que passou a ser frequentemente vista em publicações médicas a partir de 1996.

Utilizando-se de sofisticados métodos estatísticos de pareamento nestas circunstâncias, fornecidas por pacotes estatísticos, chega-se por fim à constituição de duas coortes que têm igual propensão de ingressar numa ou noutra forma de intervenção e, assim, fica-se com a pretensão de que os resultados observados sejam atribuíveis ao tratamento instituído, assemelhando-se ao que se vê em um estudo randomizado.

Os grandes estudos randomizados exigem um alto custo para sua realização, principalmente quando se trata da introdução de uma nova medicação ou dispositivo a ser comparados a uma estratégia já previamente estabelecida e onde a diferença prevista de resultados seja modesta. Tais estudos na área cardiovascular são conduzidos com milhares de pacientes.

Estudos observacionais retratam frequentemente experiências de serviços, dentro da perspectiva de sua rotina, resultado em banco de dados que pode ser de boa qualidade de aferição.

Há, obviamente, no entanto, consideráveis possíveis limitações atinentes ao estudo de escores de propensão quando comparado ao estudo randomizado.

Por exemplo, não há consideração possível para com variáveis de confundimento que não tenham sido reconhecidas na coleta de dados no estudo de escore de propensão, enquanto que no estudo randomizado elas se distribuem por chance, igualmente, no grupos observados.

Além disso, o pareamento sucessivo restringe acentuadamente o número de indivíduos que se prestam à comparação, o que acentua a possibilidade de erros do tipo 2 , principalmente, e também do tipo 1, na análise final. 
Depois, o pareamento progressivo culmina com uma apresentação assemelhada dos 2 grupos, que pode não ser, no entanto, representativa dos grupos originais, como pode ser visto na figura 1.

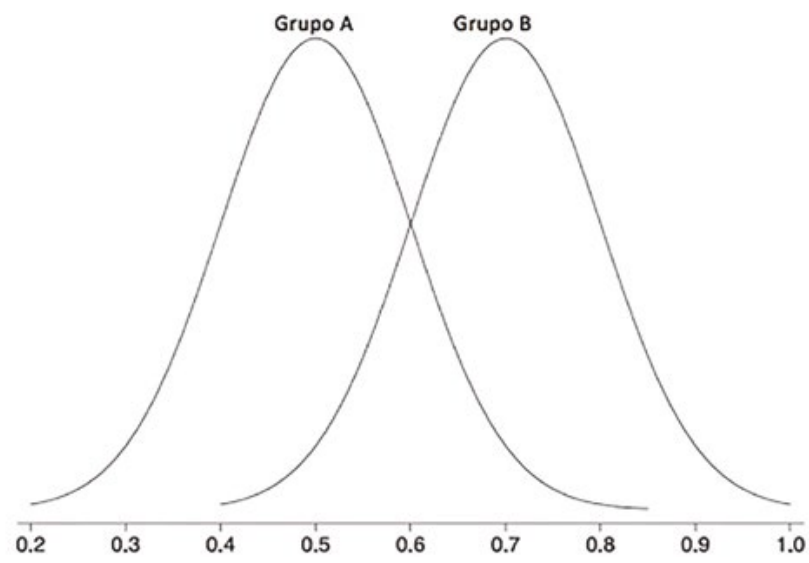

Figura 1. Propensão de escores

Onde o grupo selecionado para pareamento apresenta as maiores expressões do grupo $\mathrm{A} e$ as menores do grupo $B$.

Assim, por essas e outras razões, como por exemplo a qualidade do método de pareamento, o relato de propensão de escore deverá sempre ser visto com cautela e como gerador de hipótese, não substituindo plenamente a informação colhida por um bom estudo randomizado.

\section{REFERÊNCIAS}

1- Rosenbaum PR, Rubin DB. The central role of the propensity score in observational studies for causal effects . Biometrika .1983; 70 ( 1 ): 41 - 55 .

2- Austin PC . A critical appraisal of propensity-score matching in the medical literature between 1996 and 2003 . Stat Med .2008 ; 27 ( 12 ): 2037 - 2049

1- Editor da Revista Científica do HSI

Endereço para correspondência:

gilson-feitosa@uol.com.br 